\title{
REPERCUSSÕES PSICOFÍSICAS NA SAÚDE DOS ENFERMEIROS DA ADAPTAÇÃO E IMPROVISAÇÃO DE MATERIAIS HOSPITALARES
}

\author{
Psychophysical impact on nurses' health due to adaptation \\ and improvisation of hospital supplies
}

\section{Consecuencias sobre la salud física y psicológica del personal de enfermeria debido a la necesidad de adaptación y de improvisación de suministros hospitalarios}

\author{
Norma Valéria Dantas de Oliveira Souza ${ }^{1}$ Déborah Machado dos Santos ${ }^{2}$ Érica Lima Ramos ${ }^{3}$ Caroline Tavares da Anunciação ${ }^{4}$ \\ Priscila Cristina da Silva Thiengo ${ }^{5} \quad$ Marcela Costa Fernandes ${ }^{6}$
}

\begin{abstract}
RESUMO
Pesquisa qualitativa descritiva. 0 objeto de estudo foram as repercussões psicofísicas para a saúde dos enfermeiros diante da necessidade de adaptação e improvisação de materiais e de equipamentos para assegurar a prestação do cuidado em situação de precarização das condições de trabalho. Os objetivos foram analisar os sentimentos dos enfermeiros diante da necessidade de adaptação e de improvisação de materiais e de equipamentos no ambiente hospitalar e discutir as repercussões na saúde do enfermeiro diante desta necessidade. Os sujeitos foram 25 enfermeiros que atuavam em unidades de internação de um hospital escola da cidade do Rio de Janeiro. 0 instrumento de coleta foi a entrevista semiestruturada. Os resultados demonstraram que, devido às frequentes adaptações e improvisações de materiais, os enfermeiros sofrem repercussões negativas na saúde: medo, angústia, estresse, irritação, dores nas pernas e região lombar, cefaleia e cansaço.
\end{abstract}

Palavras-chave: Enfermagem do trabalho. Adaptação. Emoções

\begin{abstract}
It is a qualitative and descriptive research. The object of this study was the psychophysical impact on nurses' health with the need for adaptation and improvisation of materials and equipment, to ensure the provision of care in a situation of precariousness of working conditions. The objectives were analyzing nurses' feelings facing the need for adaptation and improvisation of materials and equipment at the hospital environment and discuss the impact of it on the nurses' health. The subjects were 25 nurses who used to work at admission units of a school hospital in the city of Rio de Janeiro. The data was collected applying a semi-structured interview. The results showed that, due to the frequent adjustments and improvisation of materials, the nurses have a negative impact on health, such as fear, anxiety, stress, irritation, pain in the legs and low back, headache and fatigue.
\end{abstract}

Keywords: Nursing work. Adaptation. Emotions

\section{Resumen}

Investigación de tipo cualitativo y descriptivo. El objetivo del presente estudio fue analizar las consecuencias psicofísicas que afectan la salud del personal de enfermería debido a la constante necesidad de adaptación y de improvisación de materiales y equipos para garantizar la atención y cuidado en situaciones donde las condiciones de trabajo son precarias. Los objetivos fueron analizar los sentimientos de los enfermeros frente a la necesidad de adaptación constante y de improvisación de materiales y equipos en el hospital y discutir las consecuencias que tiene sobre la salud de los enfermeros lafrecuente necesidad de improvisar y adaptar los materiales y equipos. Los sujetos del estudio fueron un grupo de 25 enfermeros que trabajaban en la unidad de admisión hospitalaria de un hospital escuela en Río de Janeiro. Se utilizó la entrevista semiestructurada para la recolección de datos. Los resultados mostraron que, debido a ajustes frecuentes e improvisaciones de los materiales, la salud de los enfermeros sufre un impacto negativo, que se manifiesta a través de sentimientos como miedo, ansiedad, estrés, enojo y de dolores físicos, como dolor de piernas, de espalda y de cabeza y fatiga.

Palabras clave: Trabajo de enfermería. Adaptación. Emociones.

\footnotetext{
Professora Adjunta do Departamento de Enfermagem Médico-Cirúrgica da Faculdade de Enfermagem da Universidade do Estado do Rio de Janeiro. Doutora em Enfermagem pela EEAN/ UFRJ. Coordenadora de Graduação da Faculdade de Enfermagem da UERJ. Brasil. E-mail: normadsouza@terra.com.br, ${ }^{2}$ Acadêmica de Enfermagem do $9^{\circ}$ período da Faculdade de Enfermagem da UERJ. Bolsista do Projeto PIBIC "Repercussões na saúde dos trabalhadores de enfermagem decorrentes da prática cotidiana de adaptar e improvisar materiais hospitalares". Brasil. E-mail: debuerj@yahoo.com.br, ${ }^{3}$ Mestre em Enfermagem pela Faculdade de Enfermagem da Universidade do Estado do Rio de Janeiro. Especialista em Enfermagem do trabalho. Brasil. E-mail: somarle@yahoo.com.br, ${ }^{4}$ Acadêmica de Enfermagem do $9^{\circ}$ período da Faculdade de Enfermagem da UERJ. Voluntária do Projeto PIBIC "Repercussões na saúde dos trabalhadores de enfermagem decorrentes da prática cotidiana de adaptar e improvisar materiais hospitalares". Brasil. E-mail: carolcta@yahoo.com.br, ${ }^{5}$ Acadêmica de Enfermagem do $9^{\circ}$ período da Faculdade de Enfermagem da UERJ. Voluntária do Projeto PIBIC "Repercussões na saúde dos trabalhadores de enfermagem decorrentes da prática cotidiana de adaptar e improvisar materiais hospitalares". Brasil. E-mail: pris.thiengo@click21.com.br., ${ }^{6}$ Acadêmica de Enfermagem do $9^{\circ}$ período da Faculdade de Enfermagem da UERJ. Voluntária do Projeto PIBIC "Repercussões na saúde dos trabalhadores de enfermagem decorrentes da prática cotidiana de adaptar e improvisar materiais hospitalares". Brasil. E-mail: marcelacostafernandes@yahoo.com.br.
} 


\section{INTRODUCÃO}

0 objeto desse estudo foram as repercussões psicofísicas dos enfermeiros diante da necessidade de adaptação e de improvisação de materiais e de equipamentos para assegurar a prestação do cuidado de enfermagem, em situação de precarização das condições de trabalho, em um hospital da rede pública de ensino.

Este objeto emergiu a partir de uma pesquisa anterior, também realizada pelos autores do presente estudo, financiada pela Universidade do Estado do Rio de Janeiro, caracterizada como Programa Institucional de Bolsas de Iniciação Científica (PIBIC), intitulada: "As inovações tecnológicas desenvolvidas pela enfermagem decorrentes da precarização do trabalho hospitalar". Seus objetivos eram identificar, no ambiente hospitalar, as adaptações e as improvisações de materiais e de equipamentos realizadas pelos trabalhadores de enfermagem decorrentes da carência qualitativa e quantitativa de recursos e discutir a importância das adaptações e das improvisações para o trabalho de enfermagem.

Os resultados dessa pesquisa evidenciaram que a enfermagem fazia múltiplas e frequentes adaptações e improvisações de materiais e de equipamentos. Tal situação revelou-se como um fator positivo para a dinâmica laboral da enfermagem, pois assegurava o cuidado e possibilitava a continuidade da assistência. No entanto, durante 0 desenvolvimento dessa pesquisa, surgiram inquietações, pois se observou empiricamente que a prática cotidiana da criação desses dispositivos, sob condiç̃es desfavoráveis de trabalho, resultava em sofrimento psíquico e em alterações no processo saúde-doença dos trabalhadores.

\section{Problematizando a Relação Enfermeiro-Trabalho no Contexto Hospitalar}

0 processo de adaptar e improvisar materiais e equipamentos tem um grande potencial para trazer repercussões psicofísicas nos trabalhadores de enfermagem devido às circunstâncias em que elas são criadas, isto é, em um contexto de precarização das condições de trabalho.

As repercussões psicofísicas são resultantes de situações ligadas à organização do trabalho e ao processo laboral, as quais se tornam desfavoráveis ao trabalhador e geram uma sobrecarga física e psíquica. Algumas destas situações são: esforço físico, levantamento e transporte manual de peso; pressão das chefias para dar conta da produtividade; acúmulo de tarefas; grau de atenção exigido, ritmo de trabalho acelerado; alto grau de variabilidade laboral; distanciamento elevado entre trabalho prescrito e trabalho real. Estas situações podem dar origem a fadiga, lombalgia, doenças osteomusculares, sofrimento psíquico e estresse. ${ }^{1}$
Verifica-se que a prática de adaptar e de improvisar materiais e equipamentos inscreve-se nas situações do elevado distanciamento entre o trabalho prescrito e o trabalho real, na alta variabilidade laboral e na pressão das chefias para manter a produtividade, originando, assim, alterações nas dimensões físicas e psíquicas do trabalhador, até gerar o adoecimento. ${ }^{1}$

A adaptação caracteriza-se no ajuste de utensílios, objetos, peças para um fim diverso daquele ao qual se destina. Entende-se como improvisar 0 ato de fazer, arranjar, inventar ou preparar rapidamente materiais e objetos os quais não são os mais adequados para determinada finalidade. ${ }^{2}$ Enfatiza-se que as adaptações e improvisações de materiais e de equipamentos que os trabalhadores de enfermagem realizam nas unidades de internações hospitalar caracterizam-se como regulações no processo de trabalho que, por sua vez, são estratégias elaboradas por eles para darem conta das demandas

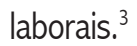

Sabe-se que, dependendo da subjetividade e das condições físicas dos trabalhadores, do contexto em que as regulações no processo laboral são realizadas, essas regulações cotidianas podem afetar negativa ou positivamente a saúde ${ }^{4}$. Desta forma, quanto maior é o distanciamento entre o trabalho prescrito (pensado e determinado pela gerência) e o trabalho real (desenvolvido pelos trabalhadores a partir do processo e das condições de trabalho), há mais necessidades de os trabalhadores fazerem regulações na dinâmica do trabalho, conduzindo-os a repercussões positivas ou negativas no processo saúde-doença. ${ }^{3}$

Ressalta-se que a falta de condições de trabalho favoráveis, na maioria das vezes, torna-se rotina e, frequentemente, não é percebida nem pelos gerentes nem pelos próprios trabalhadores, dificultando o estabelecimento de um nexo causal entre as condições de trabalho e os agravos à saúde. $^{5}$

Neste contexto de precarização das condições laborais, os profissionais de enfermagem reagem às dificuldades estabelecendo estas regulações no processo de trabalho, que surgem a partir de uma capacidade criativa peculiar de quem conhece seu trabalho e está comprometido com ele. Mas, às vezes, esta necessidade de mobilizar cotidianamente 0 potencial criativo pode resultar em ônus para a saúde. ${ }^{6}$

A responsabilidade pelo desempenho da tarefa de cuidar é própria do trabalho da enfermagem. Os profissionais de enfermagem desenvolvem ações nas esferas da promoção, da proteção e da recuperação da saúde e assistem o ser humano através de um processo de trabalho específico, o qual envolve a avaliação das condições de saúde da clientela, a prescrição e implementação de cuidados e a reavaliação de todo esse processo para, assim, elaborar novo julgamento e tomada de A 


\section{Repercusões Psicofísicas na saúde do enfermero}

pesquisa do PIBIC, anteriormente mencionada, registrou o improviso e a adaptação de vários dispositivos, como: a improvisação de patinho (utensílio usado para coletar a urina de homens que não podem ou não devem deambular até 0 sanitário); o improviso de sistemas de drenagem de ferida cirúrgica; adaptação de materiais para executar drenagem de secreção pulmonar por gravidade (drenagem postural); 0 improviso de objeto para descarte de material perfurocortante; o improviso de dispositivo com finalidade de coletar urina em pessoas portadoras de incontinência urinária; adaptação de nebulizadores em macronebulizadores; adaptação de equipamento de soro em equipamento de mensuração de PVC (Pressão Venosa Central).

Enfim, verificou-se uma diversidade de adaptações e de improvisações de materiais e equipamentos os quais resultam da mobilização da inteligência astuciosa dos trabalhadores de enfermagem que podem se transformar em tecnologias, viabilizando o cuidado de enfermagem.

No entanto, nesse contexto, também há de se investigar se a mobilização contínua da inteligência astuciosa pelos trabalhadores de enfermagem para realizarem adaptações e improvisações resultam em danos à saúde desses trabalhadores. Além disso, deve-se destacar que tais improvisações e adaptações ocorrem em um contexto laboral desfavorável caracterizado por: condições precárias de trabalho e pressão da gerência para dar conta da produtividade em uma organização de trabalho pouco racional, fragmentada e autoritária, como na maioria das instituições hospitalares da rede pública, podendo acarretar no adoecimento físico e psíquico do trabalhador de enfermagem. ${ }^{10}$

Afirmam-se ${ }^{9}$ que a organização do trabalho choca-se com as vivências subjetivas do ser humano, com sua história de vida, resultando, assim, no sofrimento, que pode se manifestar por insatisfações, medo, angústia, tédio. Por outro lado, dependendo das características do trabalhador, esta organização laboral pode motivá-lo, a partir do desejo de transformá-la, a criar algo diante das adversidades, e, à medida que consegue superar as dificuldades, emergem sentimentos de prazer e de satisfação.

Nesta perspectiva, decidiu-se realizar um estudo com os seguintes objetivos: analisar os sentimentos dos enfermeiros diante da necessidade de adaptação e de improvisação de materiais e de equipamentos no ambiente hospitalar e discutir as repercussões na saúde do enfermeiro diante da necessidade de improvisação e adaptação de materiais e de equipamentos.

É relevante neste estudo a possibilidade de se levantar informações sobre o processo de trabalho dos profissionais de enfermagem, mediante as adaptações e as improvisações de materiais e equipamentos no seu ambiente de trabalho, permitindo o reconhecimento de uma realidade que, conquanto não seja expressa em sua totalidade, possibilita apontar caminhos para um enfrentamento responsável da realidade vivenciada, buscando alcançar melhores condições de trabalho e saúde. Além disso, pontua-se como importância do estudo a possibilidade de oferecer dados para discussão sobre as repercussões na saúde do enfermeiro da realização de tal prática.

\section{METODOLOGIA}

A proposta metodológica para o estudo foi de uma abordagem qualitativa e descritiva, desenvolvida em um hospital universitário da rede pública de saúde, situado no município do Rio de Janeiro. A escolha desse cenário deveu-se ao fato de que a primeira pesquisa envolvendo a criação das adaptações e das improvisações mencionada anteriormente, e financiada pela Universidade do Estado do Rio de Janeiro, ter sido realizada nesse local.

Os sujeitos do estudo foram 25 enfermeiros que atuavam em unidades de internações, das especialidades médicas e cirúrgicas. Estas unidades e os respectivos enfermeiros foram selecionados porque antecipadamente se sabia que nestes locais esses enfermeiros realizavam um quantitativo significativo de adaptações e improvisações. Tal informação também foi apreendida através da elaboração da primeira pesquisa envolvendo a prática de adaptar e improvisar desenvolvida pelo $\mathrm{PIBIC}$, anteriormente mencionada.

Outro critério para a conformação dos sujeitos caracterizou-se no voluntariado, na disponibilidade de tempo para fornecer as informações e na aceitação livre e espontânea.

A quantidade de sujeitos do estudo foi embasada no critério de reincidência das informações; isto é, quando o conteúdo das informaç̧ões começou a se repetir foi o momento para finalizar a coleta. Além disso, por ser uma pesquisa de abordagem qualitativa, a preocupação não centrou na quantidade dos sujeitos, mas sim na qualidade destes, ou seja, na riqueza e aprofundamento das informações obtidas sobre o objeto do estudo.

0 instrumento de coleta das informações foi a entrevista semiestruturada individual. Informa-se que as entrevistas aconteceram nos meses de janeiro, fevereiro e março do ano de 2008.

Para que os enfermeiros não fossem identificados e para que se assegurasse 0 anonimato dos sujeitos, criaram-se códigos a partir da letra "E" de entrevistado e uma numeração advinda da sequência de realização das entrevistas. Assim, 0 primeiro enfermeiro entrevistado obteve a codificação $E 1$ e 0 último, E25. 
A pesquisa foi aprovada pelo Comitê de Ética da instituição onde se desenvolveu o estudo, obtendo o parecer de número 1458-CEP, que permitiu a sua execução. Primeiramente, foi entregue aos sujeitos do estudo o impresso do Termo de Consentimento Livre e Esclarecido, e, após a aprovação, foram convidados a responder a entrevista semiestruturada a qual foi gravada em aparelho de MP3 e posteriormente transcrita. Essa decisão foi tomada com base na Resolução no 196/96, que institui as Normas de Pesquisa em Saúde, as quais têm aplicação em todo o território nacional, regulamentando as pesquisas com seres humanos.

0 método de análise das entrevistas foi o da hermenêuticadialética, que é um método que realiza uma reflexão fundamental, um "caminho do pensamento", que tem como norte não se distanciar da práxis social, aprofundando-se na conjuntura histórica, social, econômica e política e buscando certa visão de conjunto, a totalidade significativa que ajuda a compreender o fenômeno investigado. ${ }^{11}$

Após a aplicabilidade dos passos preconizados pelo método da hermenêutica-dialética, surgiram duas categorias de análise: a dialética de emoções decorrente da adaptação e improvisação; e consequências da prática de adaptar e improvisar no processo saúde-doença dos trabalhadores de enfermagem

\section{ANÁLISE E TRATAMENTO DAS INFORMAÇÕES}

\section{$1^{\text {a }}$ Categoria: A dialética de emoções decorrente da adaptação e improvisação}

Os enfermeiros são unânimes em suas opiniões sobre a relevância da adaptação e da improvisação de materiais e equipamentos quando o contexto é de precarização das condições de trabalho, o qual conduz a uma insuficiência e/ou inadequação dos insumos hospitalares. Reforçam que, sem as adaptações e as improvisações, a assistência prestada ao paciente, em muitas situações, ficaria inviabilizada; porém, esses enfermeiros revelam em seus discursos a preocupação com os princípios éticos, técnicos e científicos do trabalho de enfermagem, ou seja, que mesmo diante da necessidade de adaptar e improvisar, esses princípios devem ser considerados em primeira instância. Os depoimentos selecionados a seguir caracterizam essa análise:

Eu acho, sim, importante; desde que essa improvisação não fira os princípios científicos, eu acho que deve fazer. (...) adaptar coisas em relação ao paciente, mas observando certas regras e princípios que não podem ser infringidos, que você não pode fugir. (E12)
Entretanto, apesar de os enfermeiros reconhecerem a importância das adaptações e improvisações de materiais como um fator que assegura o cuidado ao paciente, sentimentos contraditórios emergem de seus discursos. Assim, os resultados apontaram para sentimentos dialéticos como: do prazer e do sofrimento; do gratificante e do desgastante; no entanto, no contexto da complexidade das condições de trabalho dos entrevistados, o sofrimento se destacou.

As condições inadequadas de trabalho são também determinantes na qualidade do atendimento prestado pelo pessoal de enfermagem, ficando evidente que as características do cotidiano destes profissionais em hospitais são causadoras de sofrimento físico e psíquico. ${ }^{12}$

Os sentimentos de sofrimento e de desgaste emocional foram relacionados às condições materiais no trabalho, ao gasto de tempo, ao esforço físico e mental que os enfermeiros vivenciavam para conseguirem adaptar e improvisar os materiais. Também relacionavam-se ao medo acerca da qualidade do cuidado que estavam realizando.

Afirma-se, ao discorrer sobre as condições materiais no trabalho, que, nas tarefas ditas de execução, o trabalhador se vê de algum modo impedido de fazer corretamente o seu trabalho devido aos métodos e regulamentos impostos pela organização do trabalho os quais muitas vezes são incompatíveis entre si. ${ }^{4}$

A situação analisada pode ser evidenciada a partir dos discursos apresentados a seguir:

Você pensa: eu poderia estar fazendo melhor, caso eu tivesse o material adequado, eu estaria mais segura, se eu tivesse o material adequado. A assistência estaria mais garantida, a continuidade adequada dessa assistência. Aí, após pensar isso, vem a angústia, medo, revolta e outros sentimentos ruins. (E2)

Os enfermeiros precisam desenvolver um processo mental e físico para conseguir adaptar e improvisar materiais e equipamentos, ou seja, precisam pensar, planejar, reunir materiais e gerar a tal criação; e todo este processo acarreta gasto de tempo que, por sua vez, poderia ser utilizado no cuidado direto ao cliente. Esse dispêndio de tempo desnecessário resulta, também, em sentimento de ansiedade, irritabilidade e estresse profissional.

Porque o tempo que você dispende para dar conta das improvisações, o seu trabalho, é muito maior do que se vocêtivesse o material necessário, além do risco de você tambémestarferindo os princípios cientificos de trabalho. Tudo isso me irrita, mefrustra, me cansa. (E13) 


\section{Repercusões Psicofísicas na saúde do enfermero}

A busca incessante para alcançar meios que assegurem o bem-estar do paciente tem gerado sentimentos de impotência e cansaço nos enfermeiros, já que eles se sentem frustrados com a realidade que é imposta no ambiente de trabalho. Isto é, apesar de conseguirem adaptar e improvisar os materiais, 0 contexto no qual são elaboradas estas "invenções", de precarização, acabam por gerar o desânimo, a fadiga, a frustração nos enfermeiros.

Concorda-se com os autores ${ }^{13}$ quando afirmam que:

As necessidades pessoais do trabalhador de enfermagem e sua ansiedade em relação às circunstâncias com as quais ele se defronta geralmente prejudicam o tipo de atendimento que ele sabe dar e que gostaria de poder dar, podendo causar sofrimento no profissional. 13:248

Os depoimentos dos enfermeiros mostram o sofrimento psíquico decorrente de ter que adaptar e improvisar dispositivos hospitalares, pois a Instituição não disponibiliza materiais adequados ou suficientes para realização do cuidado aos pacientes.

Primeiro, eu me sinto constrangida porque eu não estou fornecendo pra aquele paciente um material adequado. Segundo, eu tenho uma frustração enorme porque a gente estuda tanto, a gente conhece as técnicas, a gente sabe o que tem que ser feito, mas a gente não tem apoio, não tem recurso, material adequado por causa do hospital, porque o hospital não fornece. Então, os sentimentos básicos são esses. (E24)

Dá uma depressão, uma tristeza muito grande, porque todo profissional deveria chegar ao mercado de trabalho e ter o campo preparado para ele executar sua técnica e desenvolver sua habilidade profissional, mas muitas vezes você perde mais tempo tentando improvisar do que propriamente para executar a técnica aprendida dentro da Universidade. (E25)

A carência quantitativa e qualitativa de materiais e equipamentos, assim como sua repercussão na saúde dos trabalhadores dos serviços públicos, tem sido objeto de interesse de outros pesquisadores, e constatou-se que,
Atualmente nos trabalhadores do serviço público, existe uma frustração pela falta de material, o que exige uma maior capacidade de improvisação desses trabalhadores para a realização de procedimento, deixando-os insatisfeitos em relação à assistência prestada ao paciente. Esses elementos somados podem desencadear 0 sofrimento no cotidiano desses trabalhadores. ${ }^{14: 235}$

$\mathrm{Na}$ fala dos enfermeiros verificou-se certo conformismo acerca das condições de trabalho por se tratar de uma instituição da rede pública. Além disso, se verificam comparações entre instituições públicas e privadas; estas últimas possibilitam o acesso a materiais de tecnologias mais arrojadas e em quantidades adequadas à prestação do cuidado aos pacientes internados.

Eu tinha muita revolta por falta da estrutura no hospital. Revolta, revolta, revolta. Mas depois você vai vendo que essa é a realidade. Que todos os enfermeiros passam por isso. (E5)

Aqui eu faço algumas adaptações e no outro, não precisa, porque o outro é particular e tem tudo o que eu quero. (E14)

Apesar de os enfermeiros relatarem ter sentimentos negativos quanto à necessidade de improvisar e adaptar materiais, o que julgavam muitas vezes um ato incorreto, eles apresentavam também alguns sentimentos de prazer e de gratificcação, quando se referiam à ajuda fornecida ao paciente e conseguiam assegurar o cuidado, superando as dificuldades. Assim, emergiam a sensação de dever cumprido e de sentimentos que os gratificavam psiquicamente. Além disso, 0 sentimento de gratificação estava ligado à possibilidade de terem criado algo útil e funcional. Verificou-se também que 0 sentimento de prazer dos trabalhadores vinculava-se ao reconhecimento do coletivo profissional pela criatividade e o bom trabalho desenvolvido a favor do cliente.

Eu acho a enfermagem muito criativa no trabalho, porque nós aprendemos na prática a técnica dentro de um princípio com tais materiais descritos dentro de uma bandeja (...) nós chegamos aqui na prática e muitas vezes nós não temos esse material, então, se você tem conteúdo científico e base teórica, 
você consegue improvisar outro material, que faz a mesma função que aquele. (E15)

Eu sinto a satisfação de ter conseguido cumprir a finalidade com a minha criatividade, isso eu sinto, (...) nós temos a satisfação de ter resolvido aquele problema, mesmo sabendo que não é ideal. (E2)

\section{$2^{\text {a }}$ Categoria: Consequências da prática de adaptar e improvisar no processo saúde- doença dos trabalhadores de enfermagem}

A prática cotidiana da elaboração de dispositivos originados das improvisações e adaptações de materiais e equipamentos, sob condições desfavoráveis de trabalho, repercute negativamente na saúde dos trabalhadores, gerando sofrimento psíquico, desgaste físico e adoecimento. Ou seja, o gasto de tempo precioso; a elevação do ritmo de trabalho causada pelas pausas forçadas para pensar/realizar as improvisações e adaptações; as idas e vindas ao posto de enfermagem para conseguir matéria-prima a fim de realizar as criações, caracterizaram-se como fonte de desgaste emocional e físico.

Neste contexto, são de grande importância a compreensão e a intervenção nas condições laborais que os trabalhadores estão submetidos. De acordo com o autor ${ }^{15}$ :

Condições de trabalho envolvem a jornada e carga de trabalho, materiais e equipamentos disponibilizados para a execução das tarefas e ambiente saudável (preservação da saúde do trabalhador). Ou seja, esse tópico analisa as condições reais oferecidas ao empregado para consecução das suas tarefas. ${ }^{15: 26}$

A análise das entrevistas revelou que a prática da improvisação e adaptação de materiais e equipamentos hospitalares gera estresse, irritação, desgaste físico, dores nas pernas e na região lombar, demonstrando que as condições de trabalho não são favoráveis à saúde dos trabalhadores. 0 depoimento apresentado a seguir revela o exposto:

(...) aí você debruça, aí aperta, não está bom, afrouxa, aí quando você termina e vê que agora ficou bom, suas pernas doem, sua coluna reclama, você está esgotada porque você se estica demais e fica toda dolorida. (E4)
Destaca-se que, com a falta de materiais, os enfermeiros precisavam deambular várias vezes ao posto de enfermagem ou até mesmo ir a outros setores a fim de selecionar e reunir os materiais necessários às adaptações e improvisações, o que também acaba resultando em desgaste físico e mental.

Você não quer ser incapaz de prestar aquela assistência, então você corre o hospital inteiro, vai numa enfermaria, pega um copo de um, um copo de outro, um cateter em outro lugar, pra dar aquela adequação naquilo que você quer fazer. (E6)

A acentuação do conflito entre a exigência de um trabalho qualificado e as possibilidades reais de sua execução, sobretudo nas profissões da área da saúde, as quais requerem atenção contínua e grande responsabilidade a cada gesto no trabalho, tornaram o sofrimento psíquico, o estresse ocupacional e a síndrome de burnoutproblemas de saúde de elevada prevalência. Esses problemas também acabam repercutindo negativamente nas relações familiares e sociais, agravando ainda mais a situação de vida do trabalhador. ${ }^{1}$

Uma parte significativa dos sujeitos relatou associação entre 0 alto nível de estresse imposto pela necessidade de adaptar e de improvisar e agravos no estado de saúde.

Estresse é 100\%. Você estressa por estar fazendo essa improvisação e estressa pelo lado humanoprofissional, quando reflete sobre o que pode estar acarretando para esse doente se algo der errado. E15

0 papel do enfermeiro no hospital tem sido apontado como altamente estressante. As responsabilidades assumidas, apesar da autonomia proporcionada, conformam uma situação para a qual confluem vários pontos de tensão. E a prática de improvisar e adaptar materiais e equipamentos são, para os enfermeiros, um grande fator de sofrimento psíquico, de estresse, de risco de burnout, de adoecimento físico e mental. Em última instância, essa complexa situação pode resultar também em absenteísmos, baixa produtividade e qualidade da assistência aquém do que poderia ser oferecida. ${ }^{16}$

\section{CONCLUSÃO}

A realidade das condições de trabalho relacionadas à precariedade nos hospitais da rede pública faz com que 0 enfermeiro apresente mais sofrimento que prazer durante a 


\section{Repercusões Psicofísicas na saúde do enfermero}

realização de suas atividades laborais. Desta forma, constatouse que esse sofrimento emerge mediante a necessidade de ter que suprir a falta de materiais através da prática da adaptação e da improvisação materiais e equipamentos, gerando frustração, irritabilidade, raiva, medo e impotência.

Verificou-se também que esta situação vivida cotidianamente leva ao conformismo dos trabalhadores, depreendendo-se que resolver esse quadro é tarefa complexa. Enfatiza-se que este sentimento de conformismo está atrelado ao fato de ser um hospital público, no qual a política neoliberal tem sua influência e, por isso, a meta é o enxugamento dos gastos pelos governos, gerando a precarização das condições e das relações laborais. ${ }^{17}$

0 sentimento de prazer surge diante da possibilidade de driblar as adversidades do dia-a-dia no trabalho, de estimular a capacidade inventiva, de criar dispositivos úteis para o processo laboral da enfermagem e de assegurar a prestação do cuidado aos pacientes, além do sentimento positivo de estar sendo útil.

Empregando uma das leis da dialética, "Unidade e Luta dos Contrários"18, considerou-se que tais sentimentos são dialéticos, em que um não é nada sem o outro, e que as citadas contradições são potencializadoras de desejos de mudanças e de processos de transformações.

Contudo, há de se ressaltar que o sofrimento advindo da prática de adaptar e improvisar materiais e equipamentos provoca repercussões na saúde do trabalhador, causando desgaste físico como dores na coluna, nos membros inferiores, cansaço. Além disso, constatou-se desgaste mental; ou seja, o estresse de tentar realizar o cuidado com a falta frequente de materiais gera irritabilidade, frustração, ansiedade e medo.

Vale ressaltar também que os trabalhadores de enfermagem, em sua maioria, trabalham em ambientes insalubres e penosos, que não oferecem condições adequadas à sua saúde, o que reforça a precarização do trabalho, seja pelo excesso de trabalho físico e mental, pelo acúmulo de horas trabalhadas, pela falta de material, pela má remuneração ou pelo vínculo empregatício que acarreta instabilidade. Essa realidade de condições de trabalho precárias acaba trazendo repercussões à saúde do trabalhador, proporcionando o adoecimento físico e mental. Entretanto, estes trabalhadores muitas vezes deixam seus desejos e vontades para segundo plano em detrimento das necessidades de clientes, da sobrevivência material, ou em detrimento da permanência no mundo do trabalho, mesmo que isso custe à perda da qualidade de vida e da saúde.

Considerando a complexidade da temática e de sua crescente efetivação nos ambientes de saúde, sugere-se que outras pesquisas sejam elaboradas, as quais investiguem, por exemplo, os impactos da prática de adaptar e improvisar materiais e equipamentos no processo e organização do trabalho em saúde, assim como as repercussões desta prática na saúde de outros profissionais que atuem no espaço hospitalar, ou ainda, para a clientela assistida. Enfim, são muitas as possibilidades de pesquisa dada a carência de conhecimento que envolve a temática e também devido às sérias repercussões que pode causar para o trabalhador, a produtividade e a clientela assistida.

\section{REFERÊNCIAS}

1. Ribeiro MCS. A nocividade do trabalho: os riscos à saúde do trabalhador. In: Ribeiro MCS, organizadora. Enfermagem e trabalho: fundamentos para a atenção à saúde dos trabalhadores. São Paulo (SP): Martinari; 2008. p.31-44.

2. Ferreira ABdeH. Novo Aurélio Século XXI. 0 Dicionário da Língua Portuguesa. Rio de Janeiro (RJ): Nova Fronteira; 1999.

3. Gueérin F et al. Compreendendo o trabalho para transformá-lo: a prática da ergonomia. São Paulo (SP): Edgard Blücher; 2001.

4. Dejours, C. A loucura do trabalho: estudo de psicopatologia do trabalho. São Paulo (SP): Cortez/Oboré; 1992.

5. Mauro MYC Projeto integrado: saúde e condições de trabalho de enfermagem no contexto do saber e da prática em instituições de assistência e de ensino nos setores público e privado. Rio de Janeiro (RJ): Faculdade de Enfermagem/ UERJ; 2005.

6. Dejours C. Inteligência prática e sabedoria prática: duas dimensões desconhecidas no trabalho. In: Lancman S, Sznelwar LI, organizadoras. Christophe Dejours: da psicopatologia do trabalho à psicodinâmica do trabalho. Rio de Janeiro (RJ): FIOCRUZ; 2004. p. 277-99.

7. Ramos EL. A qualidade de vida no trabalho: dimensões e repercussões na saúde do trabalhador de enfermagem de Terapia Intensiva [dissertação de mestrado]. Rio de Janeiro(RJ): Faculdade de Enfermagem/ UERJ; 2008.

8. Souza NVDO, Lisboa MTL. Compreendendo as estratégias coletivas de defesas das trabalhadoras de enfermagem na prática hospitalar. Esc Anna Nery Rev Enferm 2002 ago; 3(6): 425-35.

9. Dejours C, Abdoucheli E, Jayet C. Psicodinâmica do trabalho: uma contribuição da escola dejouriana à análise da relação prazer, sofrimento e trabalho. São Paulo (SP): Atlas; 1994.

10. Machado JMH, Correa MV. Conceitos de vida no trabalho na análise das relações entre processo de trabalho e saúde no hospital. Inf Epidemiol SUS 2002; 11: 159-66. 
11. Minayo MCS. Hermenêutica-dialética como caminho do pensamento social. In: Minayo MCS, Deslandes SF, organizadoras. Caminhos do pensamento: epistemologia e método. Rio de Janeiro (RJ): FIOCRUZ; 2002.

12. Marziale MHP. Enfermeiros apontam as inadequadas condições de trabalho como responsáveis pela deterioração da qualidade da assistência de enfermagem. Rev Latino-am Enfermagem. 1998 out; 6(1): 99-117.

13. Belland IL, Passos JY. Enfermagem clínica: aspectos fisiológicos e psicossociais. São Paulo (SP): EPU/ Edusp; 1978.

14. Medeiros SM, Ribeiro, LM, Fernandes, SMBA; Veras, VSD. Condições de trabalho e enfermagem: a transversalidade do sofrimento no cotidiano. REE [periódico na Internet]. 2006 ago [acesso em 15 jul 2009]; 8 (2): [aprox 7 telas.] Disponível em: http://www.fen.ufg.br/ revista/ revista8_2/v8n2a08.htm.

15. Vasconcelos AF. Qualidade de vida no trabalho: origem, evolução e perspectivas. Caderno de Pesquisas em Administração [periódico na internet]. 2001 jan/mar [citado 01 ago 2009]; 8 (1): [aprox 13 telas] Disponível em: http://www.ead.fea.usp.br/cad-pesq/arquivos/ v08-1art03.pdf.

16. Araújo TM, Aquino E, Menezes G, Santos CO, Aguiar L. Aspectos Psicossociais do trabalho e distúrbios psíquicos entre trabalhadores da enfermagem. Rev Saude Publica. 2003 ago; 37(4): 24-33.

17. Souza NVDO. Dimensão subjetiva das enfermeiras frente à organização e ao processo de trabalho em um hospital universitário. 2003. [tese de doutorado]. Rio de Janeiro (RJ): Escola de Enfermagem Anna Nery/ UFRJ; 2003.

18. Konder L. 0 que é dialética. São Paulo (SP): Brasiliense; 1992. 